\title{
Chronic Subdural Hematoma - A Dilemma to Put Drain
}

\author{
Ali MA ${ }^{1}$, Islam MA ${ }^{2}$, Chowdhury $\mathrm{RU}^{3}$, Mursalin $A^{4}$, Salek MAA ${ }^{5}$, Manik $\mathrm{AH}^{6}$, \\ Faisal $\mathrm{H}^{7}$, Islam $\mathrm{KMT}^{8}$, Mitra $\mathrm{PK}^{9}$
}

\begin{abstract}
Conflict of interest: There is no conflict of interest relevant to this paper to disclose.
\end{abstract}

Funding Agency: Was not funded by any institute or any group.

Contribution of Authors: Ali LCMA was Principal investigator, Islam CA help for protocol preparation, Chowdhury CRU, Mursalin LCA, Salek LCAA, Manik MAH, Faisal MH, Islam KMT help for data collection and Mitra PK help for editorial formatting

Copyright: @2019 Bang. JNS published by BSNS. This article is published under the creative commons CC-BY-NC license.

This license permits use distribution (https://creativecommons.orgf/ licences/by-nc/4-0/) reproduction in any medium, provided the original work is properly cited, and is not used for commercial purposes.

Received: 21 February, 2019

Accepted: 4 March, 2019

\begin{abstract}
Background: A chronic subdural hematoma (CSDH) is a collection of blood and blood breakdown products between the surface of the brain and its outermost covering the dura for more than 21 days. The elderly patients are more likely to develop a subdural hematoma, particularly from trivial trauma. CSDHs have been evacuated by burr holes, twist-drill craniotomies and craniotomies. The treatment of chronic subdural haematoma by burr hole drainage has been performed usually without using a closed drainage system, the problem of intracranial air entrapment still persists and can cause a deterioration in the level of consciousness or seizures in the postoperative period. We wanted to compare the effects of patient with drain and those without drain.
\end{abstract}

Objectives: our study is to compare the clinical outcome of CSDH with or without drain.

Methods: This prospective study was carried out at CMH Dhaka from January 2017 to July 2018; total 70 cases were investigated for the effectiveness of subdural drain. Cases were randomly allocated in two groups. Data were collected by specially designed questionnaire and analyzed by SPSS.

Results and Observation: 70 patients of CSDH were included in this study out of which 25 underwent burr hole with closed system drainage and 45 underwent burr hole without closed system drainage. They were divided into Group A and B, respectively. Among the total number of patients 14 (20\%) had shown recurrence. Out of 14 patients, 12 belong to Group B (86 \%) and 2 belong to Group a (14 \%).

Conclusion: It is concluded that, those with a closed system drainage recurrence rate is significantly lower than with burr-hole evacuation alone.

Key words: Chronic subdural hematoma (CSDH), Burr hole-evacuation (BHE), Computed tomography (CT)

Bang. J Neurosurgery 2019; 9(1): 26-32

\section{Introduction:}

Chronic subdural hematoma $(\mathrm{CSDH})$ is one of the common entities encountered in daily neurosurgical practice ${ }^{1}$. Most commonly occur in elderly (average age 63 years) population. Its incidence is $5 / 100,000$ per year in general population; because the proportion of the people aged 65 years or older is expected to be double worldwide until 2030; a large rise in incidence 2 . Approaches involving simple burr whole drainage with or without closed-system drainage have been used, with variable results $3,4,5$.

1. Lt Col (Dr.) Md Amir Ali, Surgical spl \& Neurosurgery Dept. CMH Dhaka.

2. Col (Dr.) Md. Aminul Islam, Head of dept. Neurosurgery, CMH Dhaka.

3. Col (Dr.) R U Chowdhury, Consultant Neurosurgeon, CMH Dhaka.

4. Lt Col (Dr.) Ahmed Mursalin, Surgical spl, Neurosurgery, CMH Dhaka.

5. Lt Col (Dr.) MD. Al-Amin Salek, Neurosurgeon, CMH Dhaka.

6. Maj (Dr.) Abdul Hye Manik, Neurosurgeon, CMH Dhaka.

7. Maj (Dr.) Hasnain Faisal, Neurosurgeon, CMH Dhaka.

8. Dr. K.M. Tarikul Islam, Associate prof. Dept. of Neurosurgery, BSMMU.

9. Dr. Pijush kanti Mitra, Assistant prof. Dept. of Neurosurgery, DMC.

Address of Correspondence: Lt. Col. Md. Amir Ali, Surgical spl \& Neurosurgery Dept. CMH Dhaka. Mob: 01742516625.

Email: It.col.amirali@gmail.com 
CSDH is a collection of old blood and its breakdown products between the arachnoid layer over the surface of brain parenchyma and the outermost layer called the dura ${ }^{6}$. CSDH classically occurs in the elderly and burr hole drainage is effective in $>85 \%$ of patients ${ }^{7}$. The complications of burr hole evacuation include recollection, inadequate drainage, underlying intracerebral hemorrhage, and contralateral hematoma ${ }^{8-10}$. The main problem after surgery is the intracranial accumulation of air and hemorrhage, Which causes compression of the brain.

CSDH is formed gradually by the hemorrhage from parasagittal /bridging veins following a head trauma ${ }^{11}$ . In complicated cases, such as patients with chronic alcoholism, epilepsy, hematological disorders, cerebral atrophy, and under anticoagulant therapy. Having this pathological status a minor head trauma may cause $\mathrm{CSDH}^{12}$. The major symptoms of $\mathrm{CSDH}$ are a headache, unconsciousness, confusion, and neurological deficits (contra lateral motor deficit). It may also present with mild symptoms mimicking dementia such as disorientation several weeks after a minor traumatic injury ${ }^{13}$. Patient usually ignores minor head injury and reported with gradual deterioration of neurological function. Burr hole irrigation can be done with or without closed system drainage. Several studies are going on this topic (burr hole drain or without drain) but any conclusive results has not established till now. Debate is going on whether post-operative drainage should be used with burr hole craniotomy or not. As emerging evidence suggest that it lowers the recurrence rate, but most surgeons differ it. Objective of our study is to compare the clinical outcome of CSDH with or without drain.

\section{Materials and Methods:}

This is a prospective study. All patients of CSDH who underwent operative treatment in the Neurosurgery Centre, Combined Military Hospital $(\mathrm{CMH})$ during the period from July 2016 to June 2017 were enrolled for the study. In our study mean duration from injury to detection of CSDH was 1 month and varied from 3 weeks to 3 months.

Maximum patients having history of sustained minor head injury and some patients were unable to mention about trauma. Patients having symptoms of headache, vomiting, and hemiparesis, hemiplegic, irrelevant talk, aphasia, unconsciousness.

Total of 70 cases of either sex of age group of 18 years or more were randomly selected and divided into two groups depending on the treatment procedure:
- Burr hole irrigation of hematoma cavity with closed system drainage (Group A).

- Burr hole irrigation of hematoma cavity without closed system drainage (Group B).

25 and 45 patients were included in Group A and B, respectively.

All patients were analyzed by evaluating their hospital clinical and radiological data of computerized patient record from hospital recorded picture archive and communication system.

Patients with CSDH with thickness $>10 \mathrm{~mm}$, or a midline shift $>5 \mathrm{~mm}$ on computed tomography (CT) scan were sorted and included in the study. Patients of age 18 years or more, but irrespective of gender, co-morbidities such as diabetes, hypertension, head injury; on anticoagulant, etc were included in this study.

Recurrence rate, change in hematoma size, etc., during post- operative period were compared between these two Groups (A and B).

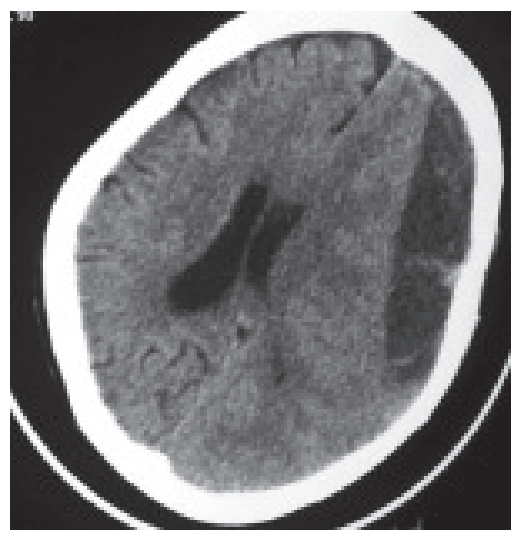

Fig.-1: Non-contrast computed tomography of head showing hypodense chronic subdural hematoma.

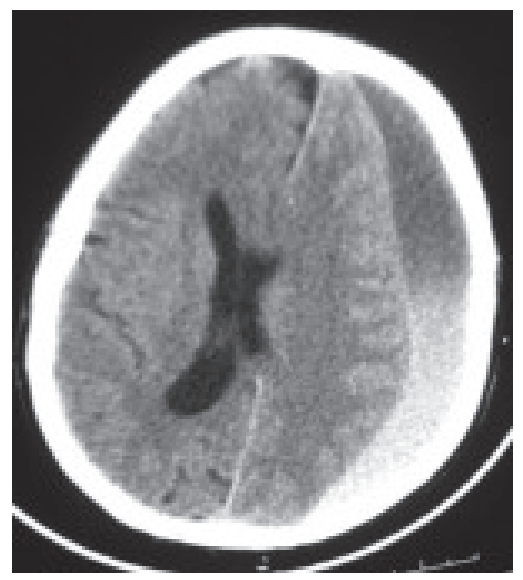

Fig.-2: Non-contrast computed tomography of head showing mixed dense chronic subdural hematoma 


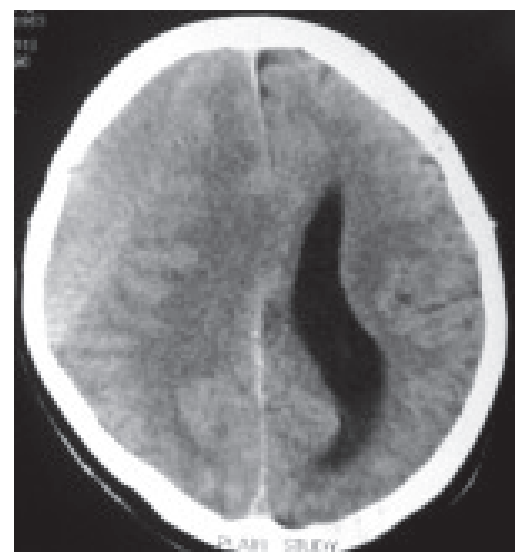

Fig.-3: Non-contrast computed tomography of head showing isodense chronic subdural hematoma

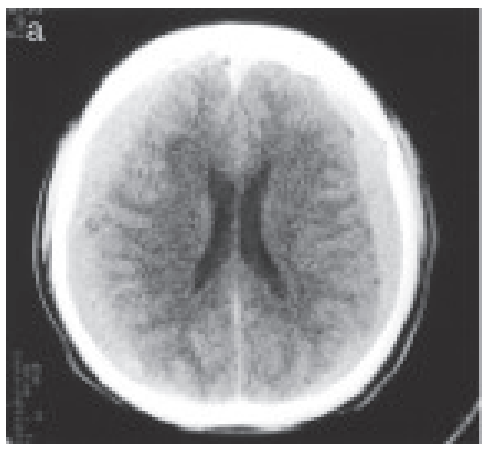

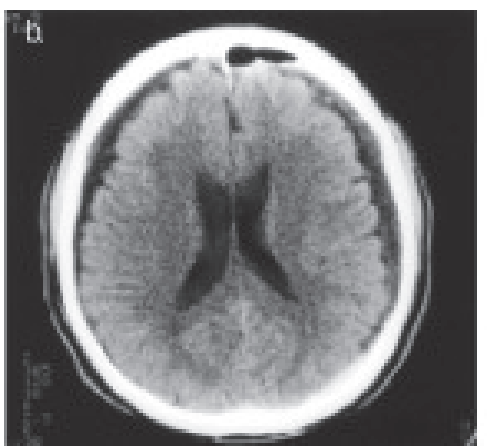

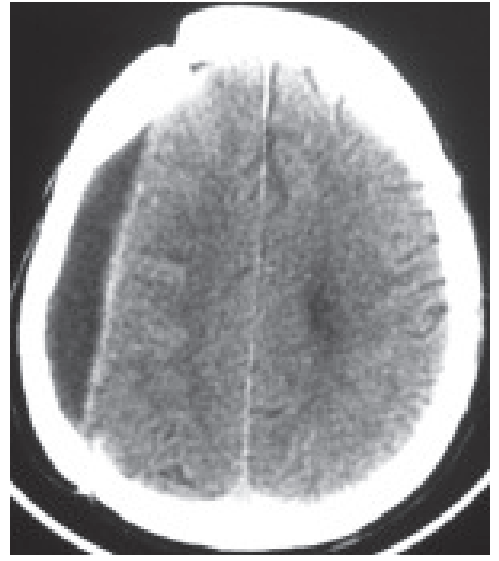

Fig.-4: Irrigation through burr hole using cannula in the treatment of chronic subdural hematoma

Fig.-5: Non-contrast computed tomography of head showing recurrence of chronic sub-dura Ihematoma

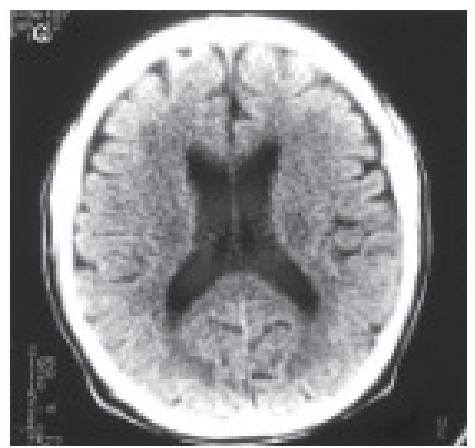

Fig.-6: Axial computed tomography scans of a patient with left chronic subdural haematoma

(a) note the significant midline shift before the drainage procedure; (b) scan at 1 week after surgery showing symmetry of the cerebrum and the minimal accumulation of air; (c) scan at approximately 6 weeks after burr hole drainage

\section{Results and Observations:}

Out of 70 cases, 25 cases were randomly selected and burr hole with closed system drainage done and 45 were underwent burr hole without closed system drainage (Figure 7) both were nominated by Group A and $B$, respectively.

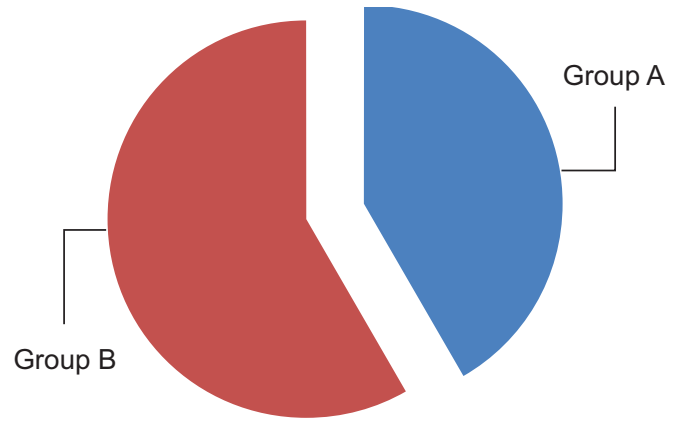

Fig -7
Males were affected more than females (male 49 and female 11, Figure 8). Age of the patients ranged from 18years to 90 years with mean age of $53 \pm 15$ years.

The most common presentation was headache $(73 \%)$ altered consciousness (22\%), hemiparesis $(3 \%)$ \& seizure $(2 \%)$ (Figure 9$)$.

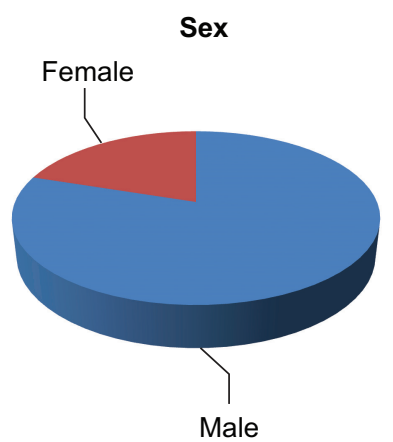

Fig -8 
$73 \%$ of the patients had a history of minor head injury in recent past (within 3 months), whereas $23 \%$ and $4 \%$ were on anti platelet and anticoagulant, respectively (Figure 10).

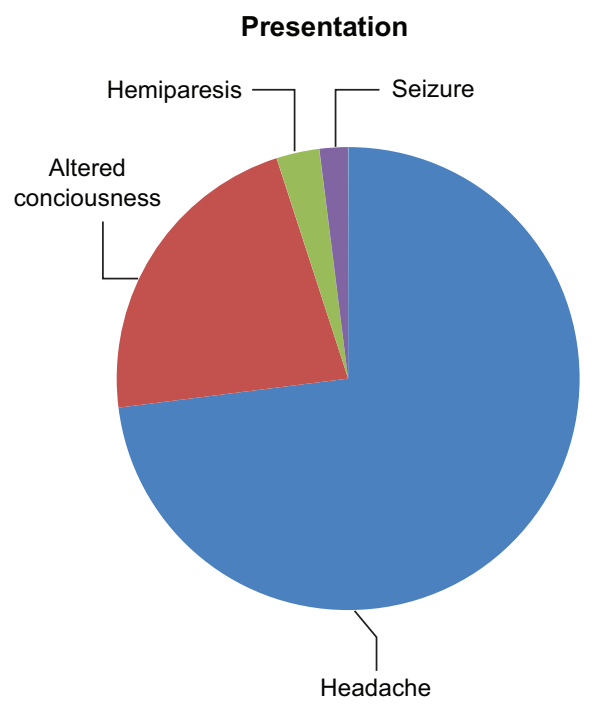

Fig -9

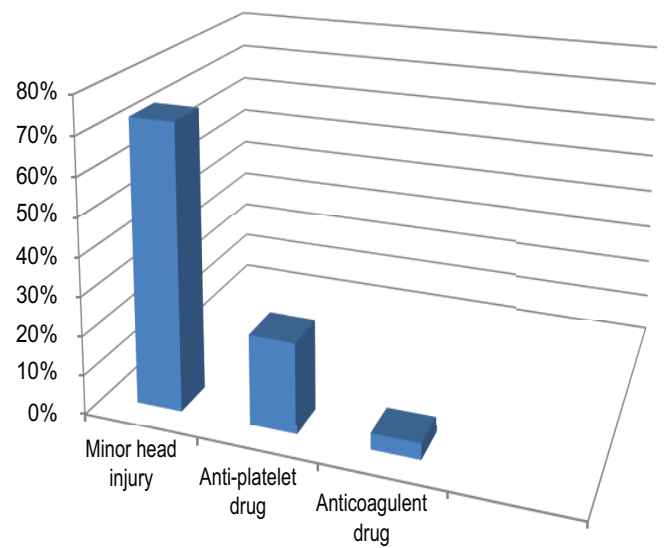

Fig -10: Aetiology

Regarding the level of consciousness by Glasgow coma score (GCS); it was found those $74 \%$ patients having GCS between 14 and 15, and 26\% patients having GCS between 5 and 13(Figure 11).

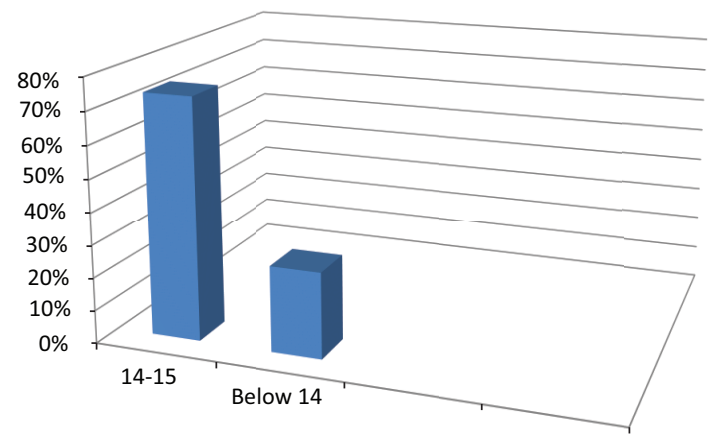

Fig.-11: Consciousness level GCS 14-15, Below 14
We followed up our patients at 1, 3, 6 months postoperatively. A follow-up evaluation was done for patients with assistance from a family member; asked about their activity of daily living and mobility status.

In this study all the patients were evaluated clinically, CT scan of head along with follow-up CT scan of head after operation to see the recurrence.

In our study $4 \%$ patients of Group A (i.e., 1 in 25 patients) developed residual hematoma with size $<10$ $\mathrm{mm}$. Whereas, in case of Group B, $18 \%$ patients (i.e., 8 in 45 patients) and $2 \%$ patients (i.e., 1 in 45 patients) developed residual hematoma $<10 \mathrm{~mm}$ and $>10 \mathrm{~mm}$, respectively.

Table-I

Distributions of number and percentage of cases of $\mathrm{CSDH}$ in different age groups

\begin{tabular}{lc}
\hline Age group (years) & $\mathrm{n}(\%)$ \\
\hline $18-20$ & $1(1)$ \\
$21-30$ & $4(6)$ \\
$31-40$ & $6(9)$ \\
$41-50$ & $13(19)$ \\
$51-60$ & $19(27)$ \\
$61-70$ & $18(26)$ \\
$71-80$ & $7(7)$ \\
$>81$ & $2(3)$ \\
\hline
\end{tabular}

Maximum patients $19(27 \%)$ were in the age group of $51-60$ years

Table-II

Number and percentage of cases of CSDHwith findings of CT scan study of head

\begin{tabular}{lc}
\hline Imaging & $\mathrm{n}(\%)$ \\
\hline Site of hematoma & $29(41)$ \\
Left & $32(46)$ \\
Right & $9(13)$ \\
Bilateral & \\
Density of hematoma & $49(70)$ \\
Hypodense & $15(21)$ \\
Isodense & $6(9)$ \\
Mixed & \\
Hematoma size $(\mathrm{mm})$ & $54(77)$ \\
$10-13$ & $14(20)$ \\
$13-15$ & $2(3)$ \\
$>15$ & \\
Midline shift $(\mathrm{mm})$ & $47(67)$ \\
$5-7$ & $22(31)$ \\
$7-10$ & $1(1)$ \\
$>10$ &
\end{tabular}


Mostly 10-13 mm 54(77\%), hypodense 49(70\%), midline shifting 5-7 mm 47 (67\%) \& haematoma 10$13 \mathrm{~mm} 54(77 \%)$

Table-III

CT findings of the recurrent hematoma

\begin{tabular}{lcc}
\hline $\begin{array}{l}\text { CT findings } \\
\text { of recurrent }\end{array}$ & Group A & Group B \\
\hline hematoma of 14 & $14 \%$ & $86 \%$ \\
Hematoma size $(\mathrm{mm})$ & 7 & 61 \\
$5-10$ & 7 & 20 \\
$10-15$ & 0 & 5 \\
$>15$ & & \\
Midline shift & 7 & 62 \\
$<5$ & 7 & 19 \\
$5-7$ & 0 & 5 \\
$>7$ & \\
\hline
\end{tabular}

Recurrence of haematoma in group $A>15$ is nil where as in group $B$ is 5

Table-IV

Post-operative complications in Groups Aand $B$ cases of CSDH total $n=18,26 \%$, group $A 5 \%$, group B 21\%

\begin{tabular}{lcc}
\hline $\begin{array}{l}\text { Post-operative } \\
\text { complications }\end{array}$ & Group A(\%) & Group B (\%) \\
\hline Headache & 2 & 7 \\
Hemiparesis & 0 & 2 \\
Seizure & 1 & 5 \\
Altered Consciousness & 1 & 4 \\
Electrolyte imbalance & 1 & 2 \\
Meningitis & 0 & 0 \\
Post-operative fever & 0 & 1 \\
\hline
\end{tabular}

Post op complication mainly headache both in group A \& group $B$

Among total of 70 patients, postoperatively 18 patients presented with symptoms most commonly with the headache and out of those 18 patients, 14 (78\%) had shown recurrence of CSDH on CT scan (Figure 2). Out of 14 patients, 12 belong to Group B (86\%) and 2 belong to Group A (14\%).

\section{Discussion:}

The methodology of management of chronic SDH varies between different centers. Burr hole craniotomy has the best cure to complication ratio and is superior to twist-drill craniotomy in the treatment of CSDH. Craniotomy and burr hole craniotomy have the lowest recurrence rate. The use of closed system drainage reduces the risk of recurrence without additional risk of complications14. In our study, it was found that most of the patients were between sixth and seventh decades (Table 1). Fogelholm and Waltimo15 estimated an incidence of 1.72/100,000 per year; the incidence increased steeply with advancing age up to $7.35 / 100,000$ per year in the age group $70-79$ and he also concluded that not only population aging but also current medical trends (such as elderly patients who receive hemodialysis, anticoagulant, and/or antiplatelet therapy) might influence the increase of $\mathrm{CSDH}$ incidence.

In this study, male: female ratio of 4.45:1 (male 49 and female 11), whereas Ahmed et al. found male: female ratio $15: 2^{2}$.

Headache is the most common symptom with $73 \%$ of patients of CSDH in our study. According to Huang et al., headaches in 30-90\% of patients of $\mathrm{CSDH}$ and Luxon and Harrison shown headaches in $64 \%$ patients as an initial symptom and $77 \%$ patients as a later symptom ${ }^{16,17}$. According to Liliang et al., young adults with CSDH usually have headache and vomiting, whereas elderly have higher frequency or mental changes or motor dysfunction ${ }^{18}$.

Santarius et al. showed $19 \%$ study population on anticoagulant drug and $14 \%$ on anti-platelet drugs ${ }^{19}$. Ahmed et al. found $76 \%$ of his study population had head injury, $11 \%$ on the anti-platelet drug, $5 \%$ on anticoagulant, and $37 \%$ were alcoholic ${ }^{2}$. In this present study, $73 \%$ of cases had a history of head trauma within few weeks. This may be due to less number of patients having anti-platelet drug as prophylactic in our country. Anti-platelet drug as prophylaxis in our country.

According to Park et al., CT scan remains the preferred diagnostic method for the $\mathrm{CSDH}^{20}$. In the present study, $70 \%$ hypodense, $21 \%$ isodense, and only $9 \%$ mixed hematoma were found in CT (Table 2 and Figure 1-3), whereas Singh et al. found $68.5 \%$ homogenous collection and $31.5 \%$ of mixed density ${ }^{22}$. Ahmed et al. found $79 \%$ hypodense, $9 \%$ isodense, and $12 \%$ mixed hematoma ${ }^{2}$. They also found $70 \%$ of patients with $5-7 \mathrm{~mm}$ midline shift, only $1 \%$ has $>10 \mathrm{~mm}$ midline shift on CT scan, bilateral hematoma 14\%, 35\% left, and on the right side $51 \%$. In the present study, it was found $13 \%$ bilateral, $46 \%$ left, $41 \%$ right. 
Singh et al. studied 200 patients out of that $9 \%$ recurrence rate in drain group and $26 \%$ without drain group, which is also statistically significant 21 .

Santarius et al. found recurrence of $9.3 \%$ with drain and $24 \%$ without drain which is statistically significant difference; he also compared mortality and morbidity in these two techniques where he found low morbidity and low mortality in drain group in 6 months followup $^{19}$. Okada et al. also found $5 \%$ recurrence in drainage group and $25 \%$ with irrigation in non-drain group; he also found that post-operative hospital stay was shorter with drainage group ${ }^{22}$. Kiymaz et al. also found continuous drainage for $\mathrm{CSDH}$ is superior to one-time drainage having with shorter hospital stay and reduced rate of recurrence ${ }^{23}$. The meta-analysis by Alcalá-Cerra et al. demonstrates that the insertion of a subdural drain was associated with a statistically significant reduction in the risk of symptomatic recurrence and the requirement for the further surgical intervention of CSDH after surgical evacuation ${ }^{24}$.

In our study recurrence of haematoma in group $\mathrm{A} 2 \%$ and group B 21\% (Table 3 and Figure 5).

In the present study, electrolyte imbalance is one of the most common complication in post-operative period with $1 \%$ in Group B and $2 \%$ in Group A. It is more compared to Ahmed et al. who found $5 \%$ and $7 \%$, respectively ${ }^{2}$. They found more incidence of limb weakness in post-operative period $37-41 \%$ compared with our study where we found only $1-3 \%$ more with drain group.

In this study total $18(26 \%)$ patients have postoperative complications in group A $5 \%$ \& group B $21 \%$. (Table 4).

Bilateral hematoma 14\%, 35\% left, and on the right side $51 \%$. In the present study, it was found $13 \%$ bilateral, $46 \%$ left, $41 \%$ right.

Singh et al. ${ }^{21}$ studied 200 patients out of that $9 \%$ recurrence rate in drain group and $26 \%$ without drain group, which is also statistically significant. Santarius et al. found recurrence of $9.3 \%$ with drain and $24 \%$ without drain which is statistically significant difference; he also compared mortality and morbidity in these two techniques which he found low morbidity and low mortality in drain group in 6 months followup ${ }^{19}$. Okada et al. also found $5 \%$ recurrence in drainage group and $25 \%$ in irrigation non-drain group; he also found that post-operative hospital stay was shorter with drainage group ${ }^{22}$. Kiymaz et al. ${ }^{23}$ also found continuous drainage for $\mathrm{CSDH}$ is superior to one-time drainage having with shorter hospital stay and reduced rate of recurrence ${ }^{23}$. The meta-analysis by Alcalá- Cerra et al. demonstrates that the insertion of a subdural drain was associated with a statistically significant reduction in the risk of symptomatic recurrence and the requirement for the further surgical intervention of CSDH after surgical evacuation ${ }^{24}$.

In our study recurrence of haematoma group A $2 \%$, group B 21\% (Table 3 and Figure 5).

\section{Conclusion:}

The aged patients are likely to develop chronic subdural haematoma which is difficult to prevent. Burr hole evacuation of haematoma remains the gold standard in these cases, although this procedure is not complication free.

The use of burr hole with drain has comparatively low recurrence rate of $\mathrm{CSDH}$ than that of the patients underwent burr hole without drain.

To minimize the post-operative complications, the placement of drain may be considered as a worthy option.

\section{References:}

1. Mori K, Maeda M. Surgical treatment of chronic subdural haematoma in 500 consecutive cases: Clinical characteristics, surgical outcome, complication, and recurrence rate. Neural Med Chir (Tokyo). 2001; 41: 371-81.

2. Ahmed MS, Agrawal D, Kale SS, Mahapatra AK. A comparative study of treatment of chronic subdural hematoma - burr-hole drainage versus continuous closed drainage. IJNT. 2011; 8:17-24.

3. Kitakami A, Ogawa A, Hakozaki S, Kidoguchi J, Obonai C, Kubo N. Carbon dioxide gas replacement of chronic subdural haematoma using single burr-hole irrigation. Surg Neurol. 1995; 43:574-8.

4. Aoki N. Subdural tapping and irrigation for the treatment of chronic subdural haematoma in adults. Neurosurgery. 1984; 14:545-8.

5. Aoki N. A new therapeutic method for chronic subdural hematoma in adults: replacement of the hematoma with oxygen via percutaneous subdural tapping. Surg Neurol. 1992; 38:253-6.

6. Kang J, Whang K, Hong SK, Pyen JS, Cho SM, Kim JY, et al. Middle meningeal artery embolization in recurrent chronic subdural hematoma combined with arachnoid cyst. Korean J Neurotrauma .2015; 11:187-90.

7. Mondorf Y, Abu-Owaimer M, Gaab MR, Oertel JM. Chronic subdural hematoma - Craniotomy versus burr-hole trepanation. Br J Neurosurg. 2009; 23:612-6. 
8. Ramamurthi B, Ganapathi K, Ramamurthi R. Intracerebral hematoma following evacuation of chronic subdural hematoma. Neurosurg Rev. 1989; 12 Suppl 1:225-7.

9. Park KJ, Kang SH, Lee HK, Chung YG. Brain stem haemorrhage following burr-hole drainage for chronic subdural hematoma-case report. Neurol Med Chir (Tokyo) 2009; 49:594-7.

10. Eom KS, Kim TY, Park JT. Contralateral acute interdural haematoma occurring after burr-hole drainage of chronic subdural haematoma. Br J Neurosurg 2009; 23:213-5.

11. Asghar M, Adhiyaman V, Greenway MW, Bhowmick BK, Bates A. Chronic subdural haematoma in the elderly - A north wales experience. J R Soc Med 2002; 95:290-2.

12. Stroobandt G, Fransen P, Thauvoy C, Menard E. Pathogenetic factors in chronic subdural haematoma and causes of recurrence after drainage. Acta Neurochir (Wien) 1995; 137:6-14

13. Richter HP, Klein HJ, Schäfer M. Chronic subdural haematomas treated by enlarged burr-hole craniotomy and closed system drainage. Retrospective study of 120 patients. Acta Neurochir (Wien) 1984; 71:179-88.

14. Weigel R, Schmiedek P, Krauss JK. Outcome of contemporary surgery for chronic subdural haematoma: Evidence based review. J Neurol Neurosurg Psychiatry 2003; 74:937-43.

15. Foelholm R, Waltimo O. Epidemiology of chronic subdural haematoma. Acta Neurochir (Wien) 1975; 32:247-50.

16. Huang $\mathrm{YH}$, Yang $\mathrm{KY}$, Lee TC, Liao CC. Bilateral chronic subdural hematoma: What is the Clinical significance? Int J Surg 2013; 11:544-8.
17. Luxon LM, Harrison MJ. Chronic subdural haematoma. Q J Med 1979; 48:43-53.

18. Liliang PC, Tsai YD, Liang CL, Lee TC, Chen HJ. Chronic subdural haematoma in young and

Extremely aged adults: A comparative study of two age groups. Injury 2002; 33:345-8.

19. Santarius T, Kirkpatrick PJ, Ganesan D, Chia HL, Jalloh I, Smielewski $\mathrm{P}$, et al. Use of drains versus no drains after burr-hole evacuation of chronic subdural haematoma: A randomised controlled trial. Lancet. 2009; 374:1067-73.

20. Park HR, Lee KS, Shim JJ, Yoon SM, Bae HG, Doh JW. Multiple densities of the chronic

subdural hematoma in CT scan. J Korean Neurosurg Soc. 2013; 54:38-41.

21. Singh AK, Suryanarayanan B, Choudhary A, Prasad A, Singh S, Gupta LN. A prospective randomized study of use of drain versus no drain after burr-hole evacuation of chronic subdural hematoma. Neurol India .2014; 62 : 169-74.

22. Okada Y, Akai T, Okamoto K, lida T, Takata H, lizuka H. A comparative study of the treatment of chronic subdural hematoma - burr-hole drainage versus burr-hole irrigation. Surg Neurol .2002; 57:405-9.

23. Kiymaz N, Yilmaz N, Mumcu C. Controversies in chronic subdural hematoma: Continuous drainage versus onetime drainage. Med Sci Monit. 2007; 13:CR240-3.

24. Alcalá-Cerra G, Young AM, Moscote-Salazar LR, Paternina-Caicedo A. Efficacy and safety of subdural drains after burr-hole evacuation of chronic subdural hematomas: Systematic review and meta-analysis of randomized controlled trials. World Neurosurg $.2014 ; 82: 1148-5$ 